\title{
Examining Piano Playing Proficiency among Selected Music Students in a Ghanaian Public University
}

\author{
Stephen Nyanney \\ Music\& Arts Atelier, P.O. box 12094, Doha, Qatar \\ *stevenyanney@gmail.com
}

\begin{abstract}
Piano instruction - composition, arrangement and tutoring has been a pivotal part of music education. Several countries across the globe have encapsulated it into curriculums and syllabi. Its benefits span several genres of music. It has been part of music education at the tertiary level in Ghana but has not received enough attention and is also faced with several challenges. The study sought to examine the piano playing proficiency among tertiary students within the Ghanaian context and the various factors responsible for the challenges faced and propose contextual interventions to address the issue. The study made use of the qualitative methodology. The instruments used for data collection were semi-structured interviews and participant observations. It was evident that piano playing among tertiary students needs rapt attention in terms of tutorials, well-equipped studio space and competent personnel to handle the tutelage. It is recommended that stakeholders shift the focal lens to piano playing proficiency in music education students as one of the requirements for graduation.
\end{abstract}

Keywords: key words, Music education, Piano lessons, Tertiary education

DOI: $10.7176 / \mathrm{JEP} / 12-17-08$

Publication date:June $30^{\text {th }} 2021$

\section{Introduction}

Music education at the tertiary level has yielded a tremendous impact both locally and internationally (Brown n.d). In Ghana, it has produced musicians, and composers of a global benchmark such as-Rev. Newlove Annan, James Varrick Armaah and many others. Music education at the pre-tertiary level in Ghana is at the fringes of art education (Wiggins and Wiggins, 2008) The major aim is to equip learners with the requisite background and expertise before enrolling on tertiary programmes (Amenyah 2017). However, most of the schools do not teach it due to the lack of specialist teachers (Wiggins and Wiggins, 2008)

The majority of the teachers handling music at the pre-tertiary level are generalist teachers. This has affected the output and interest on the part of the learners. They do not have the zeal and enthusiasm to pursue it to the highest level. The mirrored effect is replicated at the tertiary level when first-year students are admitted into the music education programmes.

The University of Education, Winneba, is an institution aimed at education of excellence to the country and the world at large. As a result, programmes are seriously taken and course units well-structured towards achieving students' professional and skills development (https://www.uew.edu.gh). The mandate of the Department of Music Education is to prepare music teachers for the pre-tertiary levels of education in Ghana. The Department seeks to train and equip students with relevant skills to teach musical arts in Ghanaian schools as well as train general musicians with appropriate skills to pursue the wide range of careers available. (https://www.uew.edu.gh)

Keyboard skill is a required area for all music students, which is taught by highly qualified instructors. In the Ghanaian context, it is assumed that once a person attends the university to pursue music as a course or reads music, he or she must be able to play the piano. For example, a colleague who is a very good musician and a choir director attended an interview for the position of a music director, and was disqualified at the end of the day because he could not perform efficiently on the piano. This scenario gives us an idea of what happens outside the walls of the music school as many people are disappointed with the performance of some music students in terms of keyboard playing (Ying, 2019) It is becoming uncertain the factors which have led to this problem. A report from the panel of judges (A small group of people who are chosen to assess student's performance on the piano) for the practical piano exams also shows that about $70 \%$ of music students perform poorly during practical piano exams.

Personal observation during mixed choruses (A gathering of music students focused on vocal technique, learning music notation, sight-singing, and preparing repertoire mainly for concerts and other special events on campus) also revealed that most student could not accompany the choir with the piano, thereby leaving few piano major students to do the job and so in their absence, a huge deficit is created in terms of skilled personnel.

During final performances (original compositions performed by students at the end of their program as part of the academic requirements) some students who are very good at piano playing are found to be under pressure because they are required to accompany most of the colleague students in their performances. Given this development, the research sought to examine piano education at the tertiary level and the various factors 
responsible for the challenges faced and propose contextual interventions to address the issue.

\section{Methodology}

The study used a qualitative methodology that sought to explore piano education at a public university in Ghana and the various factors responsible for the challenges faced and propose contextual interventions to address the issues. The researcher made use of participant observation and semi-structured interviews to gather data for the study. The paper explored the following research questions: a) what are the causes of students' inability to perform in piano playing? b) Why should piano skills be developed? c) What are the possible ways of improving piano skills tutorials? The entire study was shaped by the interpretivist paradigm.

\section{Participants}

The participants for the study were Bachelor of Education (B.Ed.) year three students in the Music Department of a public university in Ghana. The researcher used a purposive sampling technique to select the participants for the study. In terms of number, the participants were 53 students; 45 males and 8 females.

\section{Data Collection Procedure}

The main data collection instruments the researcher used were interviews and observations. The researcher interviewed the respondents during the second semester of the academic year. It was between February and May - a period of four months. For the start, the researcher had an interaction with the keyboard lecturers before embarking on the actual interview. Also, the researcher observed the B.Ed. III class in the Music Department. This was done by attending their keyboard lesson to monitor the individual performances of students on the keyboard. The researcher conducted semi-structured interviews to gather data for the study. The interviews took 10 to 20 minutes. The interviews were recorded with audio devices and transcribed into textual facts. The researcher again conducted participant observations during the keyboard lectures.

\section{Data Analysis}

The data were manually coded by the researcher, categorised and emerging themes and sub-themes captured. The researcher prepared a coding table to make the presentation of the findings easier and also for a better understanding of the whole coding process. The data were analysed qualitatively and under the qualitative approach, the researcher employed both the descriptive and narrative method.

\section{Results and Discussions}

Students' Inability to Perform In Keyboard Playing:

A respondent revealed that some students have a particular mindsets about keyboard learning. According to him, his colleagues perceive keyboard learning as a very difficult task. In view of this, they fail to exert the needed effort into practising their pieces. They easily give up the moment they encounter the slightest challenge during practice hence abandoning their pieces.

Furthermore, a participant stated that:

"There is inadequate time allocated for student lecturer interaction. The B.Ed. III music students have little time to meet their piano instructor for tutorials. Instructors spend just about five minutes guiding each student. This is woefully insufficient, looking at how practical and technical learning to play the keyboard is".

In addition, another member of the class disclosed that the school has inadequate facilities as compared to the total number of student intake. This is what he said:

"The school has a very small piano lab which could contain a few students at a time and there are only few keyboards in the piano lab summing up to ten (10). Out of these ten (10), only four (4) are functioning. In effect, it has contributed to the low performance of keyboard playing among students".

Moreover, another respondent established that unsuitable piano pieces are given out to students without considering their playing ability. She made known that; not all student have the same musical backgrounds with regards to their ability to play the keyboard prior to their tertiary education. She said that, in their class, (B.Ed. III) some colleagues have much knowledge, and some have fair knowledge and others do not know anything about the the keyboard at all. Also, everybody has a different level of learning ability. Some may be very fast in learning, others may be slow. Given this, she feels that students should be given keyboard pieces according their abilities.

The need for keyboard skill development

Keyboard skills, when developed well, would enhance students' general musicianship. Keyboard practising, involves some major elements in music, being Rhythm, aural sense, sight-reading and pitch identification i.e. (the position of notes on the staff). These will help beginners and early intermediate students improve reading ability along with listening skills. Generally, students will be able to work on simple arrangements of classical themes, along with popular songs or folk tunes. 
An interviewee said:

"Keyboard skills development will help improve the performance of students in keyboard playing".

Generally, it was noted that the performance of keyboard skills of the B.Ed. III class during examinations, were very poor. Due to this, he thinks, giving keyboard skills more attention and developing it will benefit students for academic purposes and career pursuit as well.

Possible ways of improving keyboard skills tutorials

Most respondents suggested that, instructors may have to redesign their teaching approach. They were of the view that, though the approved method of teaching at the university level is the lecture method, they can adopt the demonstrating method as well, where the lecturer would demonstrate what is required of the students.

Furthermore, another participant also indicated that:

"Expansion of the piano lab facility would help every student to have access to an instrument that will enhance their practising".

He recommended that, the university should build a modern state of the art piano lab with adequate keyboards to enable the teacher to play along or demonstrate. A custom-designed and equipped piano lab add energy and excitement to any school's music program.

Also, another respondent was of the view that, a reduction in the number of non-music related courses taken would help. He observed that, this affect the time for the students to work on their keyboard pieces for the semester.

The researcher observed that most students were complaining most often than not about keyboard skills due to some wrong perception they had about it. A lot of the students had problems with the interpretation of rhythms and also the problem of synchronizing the eye with the hand. Similarly, there is inadequate time allocated for student lecturer interaction. The students have little time to meet their piano instructor for tutorials.

The school has inadequate facilities as compared to the total number of student intake. A very small piano lab that can only contain a few students at a time. The researcher also realized that piano pieces given to students are usually above their skill level or strength, and this is attributed to the poor foundation or prior knowledge in music. In addition, the researcher noticed that students do not give the needed attention to keyboard skills as compared to the other subject areas in the Department of Music Education.

\section{Conclusion and Recommendations}

In conclusion, my findings are in significant ways symptomatic of the general picture of the lack of proficiency in piano playing amongst most music students at the tertiary level in Ghana.

I have also provided new perspectives in tackling them. My findings are that while the goal of music education (Piano tutelage) in the University of education, Winneba is quite commendable, its effective delivery is hampered by students attitude and wrong perception about learning to play the piano, inadequate time allocated for student lecturer interaction, inappropriate pieces given to students without considering their strength and prior musical background etc. etc.

I am of the view that similar research should be undertaking in other institutions in Ghana and even beyond in other to place this study in a broader context and to ascertain its widest validity for its findings. This will greatly influence the performance of Music students in keyboard playing and eventually benefit stakeholders (educators, employers' churches etc.)

Since the problem cannot be allowed to continue unsolved, the researcher has come out with the following recommendations to help remedy the situation:

The department must employ more qualified speciacialist keyboard instructors: The instructors are not able to spend more time with each student because the students are many, so when more keyboard instructors or lecturers are employed, the number of students to a lecturer will reduce hence enhance the quality of teaching.

Teaching methodology: Lecturers must demonstrate what is required of the students to arouse their interest and desire to learn to play the keyboard very well.

Expansion of piano lab facility: There is a need for the university to put up a modern piano lab with enough space to accommodate more students to enhance piano practice.

Giving piano pieces to students according to their skill level: Instructors must assess students to know their skill level before giving them their piano pieces. This will enable the lecturers to give them the appropriate piano pieces.

\section{References}

Amenyah, K.E. (2017). Student' perception of the relationship between prior knowledge and musical competencies: A case study at the University of Education, Winneba. University of Education, Winneba. http://ir.uew.edu.gh

Brown, L. (2013).The benefits of music education. /www.k-state.edu

Durbanite (2012). Piano-hand-positioning. http://durbanite.hubpages.com/hub/Piano-Hand-Positioning.htm 
Rubenstein (2012). How to play the piano. http://www.wikihow.com/play-the-piano.htm

Wiggins, R. A., \& Wiggins, J. (2008). Primary music education in the absence of specialist teachers. International Journal of Education \& the Arts, 9(12).http://www.ijea.org/v9n12/.

Ying, J. (2019). Typical problems of piano playing of students majoring in Music in Normal University. Atlantis press. https://our.oakland.edu/handle/10323/2837 